\title{
PELATIHAN MODEL PEMBELAJARAN JARAK JAUH BERBASIS APPLIKASI MOODLE SEBAGAI MEDIA PEMBELAJARAN
}

\author{
Seli Marlina Radja Leba ${ }^{1}$, Dian Mayasari², Ranta Butarbutar ${ }^{3}$ \\ 1,2,3 Universitas Musamus Merauke \\ email selly@unmus.ac.id, mayasari_fkip@unmus.ac.id,ratna@unmus.ac.id
}

\begin{abstract}
ABSTRAK
Penggunaan e-learning diyakini dapat mengatasi keterbatasan perkuliahan di kelas dan menyediakan layanan belajar yang dapat diakses dari mana saja dan kapan saja. Kegiatan pelatihan ini diharapkan dapat meningkatkan keterampilan pendidik dalam menggunakan e-learning. Pelatihan ini dilaksanakan selama satu hari melalui aplikasi webex dan didampingi oleh Gelora Jatim. Kegiatan dilaksanakan dalam bentuk simulasi, latihan, dan pemecahan masalah. Materi pelatihan adalah pedoman penggunaan e-learning berbasis Moodle untuk dosen, yang terdiri dari pengaturan mata kuliah, penambahan sumber belajar, membuat grup, memantau kemajuan belajar mahasiswa, dan penggunaan fitur forum, chatting, penugasan, kuis, dan laporan nilai. Hasil dari pelatihan dapat meningkatkan kemampuan peserta dalam memeragakan materi yang dibuktikan dengan hasil karya mereka pada laman e-learning. Dapat disimpulkan bahwa pelatihan ini penting karena dapat meningkatkan keterampilan peserta dalam mengelola pembelajaran melalui e-learning.
\end{abstract}

Kata Kunci : e-learning, Moodle, Media

\begin{abstract}
The using of e-learning believes can solve the limitations of lecturing in the classroom and provides freely learning services accessible from anywhere and anytime. This training expected to improve the skills of educators in using e-learning. It was done in full one day through the Webex application and held by Gelora Jatim. Activities carried out, such as simulations, exercises, and problem-solving. Its material is about a guideline for e-learning Moodle-based, for instances arranging courses or lessons, adding learning resources, creating groups, monitoring students' learning progress, chatting, creating assignments and quizzes, reporting scores. The results showed can improve participants ability to display their work on the e-learning page. Therefore, improvement of participants knowledge in the implementation of e-learning is the essential presence of this training.
\end{abstract}

Keywords: e-learning, Moodle, media.

\section{PENDAHULUAN}


Keadaan yang dialami oleh masyarakat Indonsia dengan adanya Covid-19, memaksa kita para pendidik untuk memanfaatkan telekomunikasi pada pembelajaran dan dipercaya dapat memperbaiki keterbatasan pembelajaran di kelas terutama dalam keadaan pandemi. Oleh sebab itu, penulis mengembangkan sistem e-learning berbantuan software Modular Object-Oriented Dynamic Learning Environment (Moodle). LMS (Learning Management System) sebagai perangkat e-lektronik modern memerlukan keterampilan khusus dalam penggunaannya. Pendidik sebenarnya sejak lama telah terbiasa dengan penggunaan teknologi informasi dalam pengelolaan pembelajaran, misalnya pembelajaran berbasis mobile atau mobile assisted learning (CALL). Tetapi dalam mengaplikasikannya belum tersistem dengan baik dan mereka menggunakannya secara sendiri-sendiri sesuai dengan kemampuannya. Pembelajaran online berbasis teknologi diantaranya: email, blog, social media, Youtube, Edmodo, dll.

Melakukan pembelajaran daring berbasis Moodle dimana banyak pendidik belum populer dibandingan dengan LMS tersebut dan belum terdapat petunjuk atau pelatihan mengenai cara menggunakan e-learning tersebut membuat para dosen belum memanfaatkannya untuk mendukung kegiatan pembelajaran. Hasil wawancara penulis dengan pendidik bahwa diperlukan kegiatan pelatihan tentang penggunaan e-learning berbasis Moodle.

Pelatihan LMS Moodle dilakukan agar para pendidik terampil dalam menggunakannya. Di antara bagian e-learning dipahami oleh pendidik adalah: 1) Mengatur topik pelajaran, 2) mendesain model pendaftaran siswa, 3) memberikan konten pembelajaran yang menarik, 4) mengkoordinir grup sesuai dengan keperluannya, 5) mengaplikasikan kuis berbasis online, 6) menggunakan bank soal, 7) memakai chat dan forum diskusi, 8) melakukan penyimpanan file pribadi, 9) memantau proses belajar siswa, 10) menggunakan fitur web conference, feedback, dan penilaian.

E-learning singkatan electronic learning ialah pembelajaran elektronik yang dilakukan dengan bantuan media online (Batubara, 2016). E-learning ialah proses pembelajaran memakai rangkaian elektronik berfungsi memberitahukan isi materi ajar serta arahan kepada siswa agar memperoleh pengetahuan sesuai dengan keperluannya (Surjono, 2013).

Terdapat dua pendapat mengenai elearning, yaitu: Electronic based e-learning dan Internet based elearning. Electronic based learning ialah tahapan pembelajaran dimana dilakukan berbantuan media elektronik internet, TV, CD-ROM, radio, dan sebagainya. Maka dari itu, internet merupakan satu 
contoh bagian e-learning. Internet Based ialah proses pembelajaran tertuju pada pemakaian internet sebagai sarana belajar (Surjono, 2016). Maka, e-learning ialah pembelajaran dimana kegiatannya berbantuan perangkat elektronik. Pemakaian teknologi komputer pada e-learning unggul selama masa wabah Covid-19 sekaligus tantangan untuk pemakaian e-learning. Maka dari itu, dalam kegiatan diperlukan pengetahuan berupa kompetensi pendidik untuk memakai e-learning, mengaplikasikan bahan buku jadi digital, serta didukung komputer, listrik, serta internet yang memadai.

\section{METODE}

Proses Pengabdian Masyarakat dilakukan dalam dua hari melalui model terpadu antara demonstrasi, latihan, serta tanya jawab. Demonstrasi, yaitu pemateri menunjukkan tahapan penggunaan bagian di e-learning secara terstruktur serta mengacu pada silabus pelatihan. Latihan merupakan tahapan selanjutnya melalui demonstrasi yang diberikan pemateri pada pelatihan e-learning. Sesi Tanya Jawab, yakni selama pelatihan, peserta diberi kesempatan untuk bertanya ketidakpahamana yang dialami saat memakai e-learning.

Materi ajar yang digunakan dalam pelaksanaan Kegiatan Program Pengabdian Kepada Masyarakat ialah sebagai berikut.

1. Kegiatan dilakukan dengan penyampaian tujuan dan silabus selama pelatihan e-learning. Dilanjutkan melalui demosntrasi serta latihan pengaturan topik materi ajar, tahapan pembelajaran, pendaftaran peserta, pengelompokan siswa, pemeriksaan peningkatan belajar siswa, pengaplikasian isi pembelajaran dengan modul page, file, folder, book, label, url, serta IMS Content Package, penggunaan bagian forum serta chatting (Muin \& Ulfah, 2012).

2. Peserta dilatih agar memahami bagian pemberian tugas pada siswa, melalui pengaturan, pemeriksaan, serta penilaian. Selanjutnya peserta diharapkan mampu membuat soal pada bank soal, mengatur pemakaian kuis online, mengelola pertanyaan kuis, serta membagi penilaian $e$ learning pada kegiatan pengabdian pada masyarakat ini ditujukan pada guru sebagai pendidik melalui webinar dengan bantuan aplikasi webex

\section{PEMBAHASAN}

Hasil kegiatan pelatihan e-learning berbasis Moodle untuk pendidik secara nasional sesuai dengan rencana jadwal yang telah disusun telah dihadiri oleh 30 orang sebagai peserta pelatihan. Adapun materi-materi pokok yang dijelaskan pada kegiatan pelatihan tersebut adalah sebagai berikut: 
Metode Pendaftaran pada situs e-learning, membuat mata pelajaran baru dan pengaturan mata kuliah, mengelola metode pendaftaran mata kuliah, mengelola peserta mata kuliah, mengisi konten mata kuliah dengan beragam jenis materi, mengelola forum dan chatting, membuat kegiatan penugasan, mengelola bank soal, membuat kegiatan kuis, serta mengelola nilai.

Pelatihan e-learning berbasis Moodle ini dilaksanakan dalam rangkaian kegiatan pengabdian pada masyarakat. Dalam hal ini, pengabdian dilaksanakan diaplikasi Webex di rumah masing-masing peserta. Adapun beberapa kendala pelatihan ini dapat dirincikan sebagai berikut.

a. Waktu pelaksanaan terlalu singkat untuk materi e-learning yang cukup padat sehingga hasilnya masih kurang maksimal. Pelaksana mengatasinya dengan menyajikan materi pelatihan secara sistematis.

b. Sebagian dosen kurang disiplin dan dosen yang memiliki jabatan struktural terkadang meninggalkan ruangan sehingga penyampaian materi kurang efektif. Untuk mengatasi hal ini, pelaksana harus memilih waktu yang tepat untuk melaksanakan pelatihan e-learning dan meminta pimpinan untuk meliburkan peserta selama kegiatan pelatihan berlangsung.

c. Pengetahuan awal sebagian dosen tentang website masih rendah sehingga instruktur harus menjelaskan dari awal dengan pelan-pelan. Sedangkan sebagian dosen lain cukup cepat dalam memahami materi, Pelaksana mengatasinya dengan meminta para peserta yang cepat tanggap untuk membantu peserta yang lambat agar semua materi dapat disampaikan dengan efesien.

d. Koneksi internet kurang stabil pada siang hari karena civitas akademik banyak yang menggunakan.

\section{SIMPULAN}

Berdasarkan hasil kegiatan pelatihan e-learning berbasis Moodle dapat disimpulkan bahwa peserta sangat antusis dalam mengikutinya dari awal hingga sesi terakhir kegiatan. Hal ini dibuktikan dengan banyaknya jumlah peserta yang bertanya secara bergantian bahkan mengimplemenasikan pertanyaan di dalam room chatting.

Tim pelaksana menyarankan agar pimpinan Universitas kiranya dapat memberikan ruang dan kesempatan kepada seluruh dosen untuk tetap mengembangkan sistem pembelajaran yang berbasis teknologi elektronik maupun digital.

\section{DAFTAR PUSTAKA}

Batubara, H. H. 2016. Penggunaan Google Form Sebagai Alat Penilaian Kinerja Dosen Di Prodi Pgmi Uniska 
Jurnal Pengamas, Vol.3, No.2, Desember (2020) e-ISSN: 2622-383X

Muhammad Arsyad Al Banjari. Jurnal Pendidikan Dasar Islam, 8 (1). https://www.google.com/intl/id/forms/about/

Butarbutar, R., Uspayanti, R., Bawawa, M., Leba, S. M. R. 2020. Mobile Assisted Language Learning. In 3rd International Conference on Social Sciences (ICSS 2020) (pp. 390-392). Atlantis Press.

Hamidi, A. L., Sriyanto, A., Warto, Fakthurrozi, Suprisdiantoko. (n.d.). Panduan E-Learning.

Muin, A., \& Ulfah, M. R. 2012. Meningkatkan Hasil Belajar Matematika Siswadengan Pembelajaran Menggunakan Aplikasimoodle. Pythagoras, 7(1). https://doi.org/10.21831/pg.v7i1.2838

Siswa, LoginSurjono, H. D. 2016. Panduan penggunaan moodle untuk guru SMK Sulawesi Selatan (M. Irhas (ed.); Cetakan Pe). Pt Ebimbel Indonesia.

Surjono, H. D. 2013. Membangun Course E-Learning Berbasis Moodle Herman Dwi Surjono. Membangun Course E-Learning Berbasis Moodle, 1-196. 